\title{
Recommendations for the Conduct, Reporting, Editing, and Publication of Scholarly Work in Medical Journals
}

\section{Updated May 2022}

I. About the Recommendations

A. Purpose of the Recommendations

B. Who Should Use the Recommendations?

C. History of the Recommendations

II. Roles and Responsibilities of Authors, Contributors, Reviewers, Editors, Publishers, and Owners

A. Defining the Role of Authors and Contributors

1. Why Authorship Matters

2. Who Is an Author?

3. Non-Author Contributors

B. Disclosure of Financial and Non-Financial Relationships and Activities, and Conflicts of Interest

1. Participants
a. Authors
b. Peer Reviewers
c. Editors and Journal Staff

2. Reporting Relationships and Activities

C. Responsibilities in the Submission and Peer-Review Process

1. Authors

a. Predatory or Pseudo-Journals

2. Journals
a. Confidentiality
b. Timeliness
c. Peer Review
d. Integrity
e. Diversity and Inclusion
f. Journal Metrics

3. Peer Reviewers

D. Journal Owners and Editorial Freedom

1. Journal Owners

2. Editorial Freedom

E. Protection of Research Participants

III. Publishing and Editorial Issues Related to Publication in Medical Journals

A. Corrections, Retractions, Republications, and Version Control

B. Scientific Misconduct, Expressions of Concern, and Retraction

C. Copyright

D. Overlapping Publications

1. Duplicate Submission

2. Duplicate and Prior Publication

3. Preprints

a. Choosing a Preprint Archive

b. Submitting Manuscripts That Are in Preprint Archives to a Peer-Reviewed Journal

c. Referencing Preprints in Submitted Manuscripts

4. Acceptable Secondary Publication

5. Manuscripts Based on the Same Database

E. Correspondence

F. Fees
G. Supplements, Theme Issues, and Special Series

H. Sponsorship and Partnerships

I. Electronic Publishing

J. Advertising

K. Journals and the Media

L. Clinical Trials

1. Registration

2. Data Sharing

IV. Manuscript Preparation and Submission

A. Preparing a Manuscript for Submission to a Medical Journal

1. General Principles

2. Reporting Guidelines

3. Manuscript Sections
a. Title Page
b. Abstract
c. Introduction
d. Methods

i. Selection and Description of Participants

ii. Technical Information

iii. Statistics

e. Results

f. Discussion

g. References

i. General Considerations

ii. Style and Format

h. Tables

i. Illustrations (Figures)

j. Units of Measurement

k. Abbreviations and Symbols

B. Sending the Manuscript to the Journal

\section{About the Recommendations}

\section{A. Purpose of the Recommendations}

ICMJE developed these recommendations to review best practice and ethical standards in the conduct and reporting of research and other material published in medical journals, and to help authors, editors, and others involved in peer review and biomedical publishing create and distribute accurate, clear, reproducible, unbiased medical journal articles. The recommendations may also provide useful insights into the medical editing and publishing process for the media, patients and their families, and general readers.

\section{B. Who Should Use the Recommendations?}

These recommendations are intended primarily for use by authors who might submit their work for publication to ICMJE member journals. Many non-ICMJE journals voluntarily use these recommendations (see www.icmje.org/ journals-following-the-icmje-recommendations/). The ICMJE encourages that use but has no authority to monitor or 
Recommendations for the Conduct, Reporting, Editing, and Publication of Scholarly Work in Medical Journals

enforce it. In all cases, authors should use these recommendations along with individual journals' instructions to authors. Authors should also consult guidelines for the reporting of specific study types (e.g., the CONSORT guidelines for the reporting of randomized trials); see www.equator-network.org.

Journals that follow these recommendations are encouraged to incorporate them into their instructions to authors and to make explicit in those instructions that they follow ICMJE recommendations. Journals that wish to be identified on the ICMJE website as following these recommendations should notify the ICMJE secretariat at www. icmje.org/journals-following-the-icmje-recommendations/ journal-listing-request-form/. Journals that in the past have requested such identification but who no longer follow ICMJE recommendations should use the same means to request removal from this list.

The ICMJE encourages wide dissemination of these recommendations and reproduction of this document in its entirety for educational, not-for-profit purposes without regard for copyright, but all uses of the recommendations and document should direct readers to www. icmje.org for the official, most recent version, as the ICMJE updates the recommendations periodically when new issues arise.

\section{History of the Recommendations}

The ICMJE has produced multiple editions of this document, previously known as the Uniform Requirements for Manuscripts Submitted to Biomedical Journals (URMs). The URM was first published in 1978 as a way of standardizing manuscript format and preparation across journals. Over the years, issues in publishing that went well beyond manuscript preparation arose, resulting in the development of separate statements, updates to the document, and its renaming as "Recommendations for the Conduct, Reporting, Editing, and Publication of Scholarly Work in Medical Journals" to reflect its broader scope. Previous versions of the document may be found in the "Archives" section of www.icmje.org.

\section{Roles And Responsibilities of Authors, Contributors, Reviewers, Editors, Publishers, and Owners}

\section{A. Defining the Role of Authors and Contributors 1. Why Authorship Matters}

Authorship confers credit and has important academic, social, and financial implications. Authorship also implies responsibility and accountability for published work. The following recommendations are intended to ensure that contributors who have made substantive intellectual contributions to a paper are given credit as authors, but also that contributors credited as authors understand their role in taking responsibility and being accountable for what is published.

Because authorship does not communicate what contributions qualified an individual to be an author, some journals now request and publish information about the contributions of each person named as having participated in a submitted study, at least for original research. Editors are strongly encouraged to develop and implement a contributorship policy. Such policies remove much of the ambiguity surrounding contributions, but leave unresolved the question of the quantity and quality of contribution that qualify an individual for authorship. The ICMJE has thus developed criteria for authorship that can be used by all journals, including those that distinguish authors from other contributors.

\section{Who Is an Author?}

The ICMJE recommends that authorship be based on the following 4 criteria:

1. Substantial contributions to the conception or design of the work; or the acquisition, analysis, or interpretation of data for the work; AND

2. Drafting the work or revising it critically for important intellectual content; AND

3. Final approval of the version to be published; AND

4. Agreement to be accountable for all aspects of the work in ensuring that questions related to the accuracy or integrity of any part of the work are appropriately investigated and resolved.

In addition to being accountable for the parts of the work he or she has done, an author should be able to identify which co-authors are responsible for specific other parts of the work. In addition, authors should have confidence in the integrity of the contributions of their co-authors.

All those designated as authors should meet all four criteria for authorship, and all who meet the four criteria should be identified as authors. Those who do not meet all four criteria should be acknowledged-see Section II. A.3 below. These authorship criteria are intended to reserve the status of authorship for those who deserve credit and can take responsibility for the work. The criteria are not intended for use as a means to disqualify colleagues from authorship who otherwise meet authorship criteria by denying them the opportunity to meet criterion \#s 2 or 3. Therefore, all individuals who meet the first criterion should have the opportunity to participate in the review, drafting, and final approval of the manuscript.

The individuals who conduct the work are responsible for identifying who meets these criteria and ideally should do so when planning the work, making modifications as appropriate as the work progresses. We encourage collaboration and co-authorship with colleagues in the locations where the research is conducted. It is the collective responsibility of the authors, not the journal to which the work is submitted, to determine that all people named as authors meet all four criteria; it is not the role of journal editors to determine who qualifies or does not qualify for authorship or to arbitrate authorship conflicts. If agreement cannot be reached about who qualifies for authorship, the institution(s) where the work was performed, not the journal editor, should be asked to investigate. The criteria used to determine the order in which authors are listed on the byline may vary, and are to be decided collectively by the author group and not by 
Recommendations for the Conduct, Reporting, Editing, and Publication of Scholarly Work in Medical Journals

editors. If authors request removal or addition of an author after manuscript submission or publication, journal editors should seek an explanation and signed statement of agreement for the requested change from all listed authors and from the author to be removed or added.

The corresponding author is the one individual who takes primary responsibility for communication with the journal during the manuscript submission, peer-review, and publication process. The corresponding author typically ensures that all the journal's administrative requirements, such as providing details of authorship, ethics committee approval, clinical trial registration documentation, and disclosures of relationships and activities, are properly completed and reported, although these duties may be delegated to one or more co-authors. The corresponding author should be available throughout the submission and peer-review process to respond to editorial queries in a timely way, and should be available after publication to respond to critiques of the work and cooperate with any requests from the journal for data or additional information should questions about the paper arise after publication. Although the corresponding author has primary responsibility for correspondence with the journal, the ICMJE recommends that editors send copies of all correspondence to all listed authors.

When a large multi-author group has conducted the work, the group ideally should decide who will be an author before the work is started and confirm who is an author before submitting the manuscript for publication. All members of the group named as authors should meet all four criteria for authorship, including approval of the final manuscript, and they should be able to take public responsibility for the work and should have full confidence in the accuracy and integrity of the work of other group authors. They will also be expected as individuals to complete disclosure forms.

Some large multi-author groups designate authorship by a group name, with or without the names of individuals. When submitting a manuscript authored by a group, the corresponding author should specify the group name if one exists, and clearly identify the group members who can take credit and responsibility for the work as authors. The byline of the article identifies who is directly responsible for the manuscript, and MEDLINE lists as authors whichever names appear on the byline. If the byline includes a group name, MEDLINE will list the names of individual group members who are authors or who are collaborators, sometimes called non-author contributors, if there is a note associated with the byline clearly stating that the individual names are elsewhere in the paper and whether those names are authors or collaborators.

\section{Non-Author Contributors}

Contributors who meet fewer than all 4 of the above criteria for authorship should not be listed as authors, but they should be acknowledged. Examples of activities that alone (without other contributions) do not qualify a contributor for authorship are acquisition of funding; general supervision of a research group or general administrative support; and writing assistance, technical editing, language editing, and proofreading. Those whose contributions do not justify authorship may be acknowledged individually or together as a group under a single heading (e.g., "Clinical Investigators" or "Participating Investigators"), and their contributions should be specified (e.g., "served as scientific advisors," "critically reviewed the study proposal," "collected data," "provided and cared for study patients," "participated in writing or technical editing of the manuscript").

Because acknowledgment may imply endorsement by acknowledged individuals of a study's data and conclusions, editors are advised to require that the corresponding author obtain written permission to be acknowledged from all acknowledged individuals.

\section{B. Disclosure of Financial and Non-Financial Relationships and Activities, and Conflicts of Interest}

Public trust in the scientific process and the credibility of published articles depend in part on how transparently an author's relationships and activities, directly or topically related to a work, are handled during the planning, implementation, writing, peer review, editing, and publication of scientific work.

The potential for conflict of interest and bias exists when professional judgment concerning a primary interest (such as patients' welfare or the validity of research) may be influenced by a secondary interest (such as financial gain). Perceptions of conflict of interest are as important as actual conflicts of interest.

Individuals may disagree on whether an author's relationships or activities represent conflicts. Although the presence of a relationship or activity does not always indicate a problematic influence on a paper's content, perceptions of conflict may erode trust in science as much as actual conflicts of interest. Ultimately, readers must be able to make their own judgments regarding whether an author's relationships and activities are pertinent to a paper's content. These judgments require transparent disclosures. An author's complete disclosure demonstrates a commitment to transparency and helps to maintain trust in the scientific process.

Financial relationships (such as employment, consultancies, stock ownership or options, honoraria, patents, and paid expert testimony) are the most easily identifiable, the ones most often judged to represent potential conflicts of interest and thus the most likely to undermine the credibility of the journal, the authors, and science itself. Other interests may also represent or be perceived as conflicts, such as personal relationships or rivalries, academic competition, and intellectual beliefs.

Authors should avoid entering into agreements with study sponsors, both for-profit and nonprofit, that interfere with authors' access to all of the study's data or that interfere with their ability to analyze and interpret the data and to prepare and publish manuscripts independently when and where they choose. Policies that dictate where authors may publish their work violate this 
Recommendations for the Conduct, Reporting, Editing, and Publication of Scholarly Work in Medical Journals

principle of academic freedom. Authors may be required to provide the journal with the agreements in confidence.

Purposeful failure to report those relationships or activities specified on the journal's disclosure form is a form of misconduct, as is discussed in Section III.B.

\section{Participants}

All participants in the peer-review and publication process-not only authors but also peer reviewers, editors, and editorial board members of journals-must consider and disclose their relationships and activities when fulfilling their roles in the process of article review and publication.

\section{a. Authors}

When authors submit a manuscript of any type or format they are responsible for disclosing all relationships and activities that might bias or be seen to bias their work. The ICMJE has developed a Disclosure Form to facilitate and standardize authors' disclosures. ICMJE member journals require that authors use this form, and ICMJE encourages other journals to adopt it.

\section{b. Peer Reviewers}

Reviewers should be asked at the time they are asked to critique a manuscript if they have relationships or activities that could complicate their review. Reviewers must disclose to editors any relationships or activities that could bias their opinions of the manuscript, and should recuse themselves from reviewing specific manuscripts if the potential for bias exists. Reviewers must not use knowledge of the work they're reviewing before its publication to further their own interests.

\section{c. Editors and Journal Staff}

Editors who make final decisions about manuscripts should recuse themselves from editorial decisions if they have relationships or activities that pose potential conflicts related to articles under consideration. Other editorial staff members who participate in editorial decisions must provide editors with a current description of their relationships and activities (as they might relate to editorial judgments) and recuse themselves from any decisions in which an interest that poses a potential conflict exists. Editorial staff must not use information gained through working with manuscripts for private gain. Editors should regularly publish their own disclosure statements and those of their journal staff. Guest editors should follow these same procedures.

Journals should take extra precautions and have a stated policy for evaluation of manuscripts submitted by individuals involved in editorial decisions. Further guidance is available from COPE (https://publicationethics.org/files/ A_Short_Guide_to_Ethical_Editing.pdf) and WAME (http:// wame.org/conflict-of-interest-in-peer-reviewed-medicaljournals).

\section{Reporting Relationships and Activities}

Articles should be published with statements or supporting documents, such as the ICMJE Disclosure Form, declaring:

- Authors' relationships and activities; and
- Sources of support for the work, including sponsor names along with explanations of the role of those sources if any in study design; collection, analysis, and interpretation of data; writing of the report; any restrictions regarding the submission of the report for publication; or a statement declaring that the supporting source had no such involvement or restrictions regarding publication; and

- Whether the authors had access to the study data, with an explanation of the nature and extent of access, including whether access is ongoing.

To support the above statements, editors may request that authors of a study sponsored by a funder with a proprietary or financial interest in the outcome sign a statement, such as "I had full access to all of the data in this study and I take complete responsibility for the integrity of the data and the accuracy of the data analysis."

\section{Responsibilities in the Submission and Peer-Review Process 1. Authors}

Authors should abide by all principles of authorship and declaration of relationships and activities detailed in Sections II.A and II.B of this document.

\section{a. Predatory or Pseudo-Journals}

A growing number of entities are advertising themselves as "scholarly medical journals" yet do not function as such. These journals ("predatory" or "pseudo-journals") accept and publish almost all submissions and charge article processing (or publication) fees, often informing authors about this after a paper's acceptance for publication. They often claim to perform peer review but do not and may purposefully use names similar to well-established journals. They may state that they are members of ICMJE but are not (see www.icmje.org for current members of the ICMJE) and that they follow the recommendations of organizations such as the ICMJE, COPE, and WAME. Researchers must be aware of the existence of such entities and avoid submitting research to them for publication. Authors have a responsibility to evaluate the integrity, history, practices, and reputation of the journals to which they submit manuscripts. Guidance from various organizations is available to help identify the characteristics of reputable peer-reviewed journals (www.wame.org/identifying-predatory-or-pseudojournals and www.wame.org/principles-of-transparencyand-best-practice-in-scholarly-publishing).

Seeking the assistance of scientific mentors, senior colleagues, and others with many years of scholarly publishing experience may also be helpful.

Authors should avoid citing articles in predatory or pseudo-journals.

\section{Journals}

\section{a. Confidentiality}

Manuscripts submitted to journals are privileged communications that are authors' private, confidential property, and authors may be harmed by premature disclosure of any or all of a manuscript's details. 


\section{Recommendations for the Conduct, Reporting, Editing, and Publication of Scholarly Work in Medical Journals}

Editors therefore must not share information about manuscripts, including whether they have been received and are under review, their content and status in the review process, criticism by reviewers, and their ultimate fate, to anyone other than the authors and reviewers. Requests from third parties to use manuscripts and reviews for legal proceedings should be politely refused, and editors should do their best not to provide such confidential material should it be subpoenaed.

Editors must also make clear that reviewers should keep manuscripts, associated material, and the information they contain strictly confidential. Reviewers and editorial staff members must not publicly discuss the authors' work, and reviewers must not appropriate authors' ideas before the manuscript is published. Reviewers must not retain the manuscript for their personal use and should destroy paper copies of manuscripts and delete electronic copies after submitting their reviews.

When a manuscript is rejected, it is best practice for journals to delete copies of it from their editorial systems unless retention is required by local regulations. Journals that retain copies of rejected manuscripts should disclose this practice in their Information for Authors.

When a manuscript is published, journals should keep copies of the original submission, reviews, revisions, and correspondence for at least three years and possibly in perpetuity, depending on local regulations, to help answer future questions about the work should they arise.

Editors should not publish or publicize peer reviewers' comments without permission of the reviewer and author. If journal policy is to blind authors to reviewer identity and comments are not signed, that identity must not be revealed to the author or anyone else without the reviewers' expressed written permission.

Confidentiality may have to be breached if dishonesty or fraud is alleged, but editors should notify authors or reviewers if they intend to do so and confidentiality must otherwise be honored.

\section{b. Timeliness}

Editors should do all they can to ensure timely processing of manuscripts with the resources available to them. If editors intend to publish a manuscript, they should attempt to do so in a timely manner and any planned delays should be negotiated with the authors. If a journal has no intention of proceeding with a manuscript, editors should endeavor to reject the manuscript as soon as possible to allow authors to submit to a different journal.

\section{c. Peer Review}

Peer review is the critical assessment of manuscripts submitted to journals by experts who are usually not part of the editorial staff. Because unbiased, independent, critical assessment is an intrinsic part of all scholarly work, including scientific research, peer review is an important extension of the scientific process.

The actual value of peer review is widely debated, but the process facilitates a fair hearing for a manuscript among members of the scientific community. More practically, it helps editors decide which manuscripts are suitable for their journals. Peer review often helps authors and editors improve the quality of reporting.

It is the responsibility of the journal to ensure that systems are in place for selection of appropriate reviewers. It is the responsibility of the editor to ensure that reviewers have access to all materials that may be relevant to the evaluation of the manuscript, including supplementary material for e-only publication, and to ensure that reviewer comments are properly assessed and interpreted in the context of their declared relationships and activities.

A peer-reviewed journal is under no obligation to send submitted manuscripts for review, and under no obligation to follow reviewer recommendations, favorable or negative. The editor of a journal is ultimately responsible for the selection of all its content, and editorial decisions may be informed by issues unrelated to the quality of a manuscript, such as suitability for the journal. An editor can reject any article at any time before publication, including after acceptance if concerns arise about the integrity of the work.

Journals may differ in the number and kinds of manuscripts they send for review, the number and types of reviewers they seek for each manuscript, whether the review process is open or blinded, and other aspects of the review process. For this reason and as a service to authors, journals should publish a clear, transparent description of their peer-review process for all types of manuscripts.

Journals should notify reviewers of the ultimate decision to accept or reject a paper, and should acknowledge the contribution of peer reviewers to their journal. Editors are encouraged to share reviewers' comments with co-reviewers of the same paper, so reviewers can learn from each other in the review process.

As part of peer review, editors are encouraged to review research protocols, plans for statistical analysis if separate from the protocol, and/or contracts associated with project-specific studies. Editors should encourage authors to make such documents publicly available at the time of or after publication, before accepting such studies for publication. Some journals may require public posting of these documents as a condition of acceptance for publication.

Journal requirements for independent data analysis and for public data availability are in flux at the time of this revision, reflecting evolving views of the importance of data availability for pre- and post-publication peer review. Some journal editors currently request a statistical analysis of trial data by an independent biostatistician before accepting studies for publication. Others ask authors to say whether the study data are available to third parties to view and/or use/reanalyze, while still others encourage or require authors to share their data with others for review or reanalysis. Each journal should establish and publish their specific requirements for data analysis and post in a place that potential authors can easily access. 
Recommendations for the Conduct, Reporting, Editing, and Publication of Scholarly Work in Medical Journals

Some people believe that true scientific peer review begins only on the date a paper is published. In that spirit, medical journals should have a mechanism for readers to submit comments, questions, or criticisms about published articles, and authors have a responsibility to respond appropriately and cooperate with any requests from the journal for data or additional information should questions about the paper arise after publication (see Section III).

ICMJE believes investigators have a duty to maintain the primary data and analytic procedures underpinning the published results for at least 10 years. The ICMJE encourages the preservation of these data in a data repository to ensure their longer-term availability.

\section{d. Integrity}

Editorial decisions should be based on the relevance of a manuscript to the journal and on the manuscript's originality, quality, and contribution to evidence about important questions. Those decisions should not be influenced by commercial interests, personal relationships or agendas, or findings that are negative or that credibly challenge accepted wisdom. In addition, authors should submit for publication or otherwise make publicly available, and editors should not exclude from consideration for publication, studies with findings that are not statistically significant or that have inconclusive findings. Such studies may provide evidence that, combined with that from other studies through meta-analysis, might still help answer important questions, and a public record of such negative or inconclusive findings may prevent unwarranted replication of effort or otherwise be valuable for other researchers considering similar work.

Journals should clearly state their appeals process and should have a system for responding to appeals and complaints.

\section{e. Diversity and Inclusion}

To improve academic culture, editors should seek to engage a broad and diverse array of authors, reviewers, editorial staff, editorial board members, and readers.

\section{f. Journal Metrics}

The journal impact factor is widely misused as a proxy for research and journal quality and as a measure of the importance of specific research projects or the merits of individual researchers, including their suitability for hiring, promotion, tenure, prizes, or research funding. ICMJE recommends that journals reduce the emphasis on impact factor as a single measure, but rather provide a range of article and journal metrics relevant to their readers and authors.

\section{Peer Reviewers}

Manuscripts submitted to journals are privileged communications that are authors' private, confidential property, and authors may be harmed by premature disclosure of any or all of a manuscript's details.

Reviewers therefore should keep manuscripts and the information they contain strictly confidential. Reviewers must not publicly discuss authors' work and must not appropriate authors' ideas before the manu- script is published. Reviewers must not retain the manuscript for their personal use and should destroy copies of manuscripts after submitting their reviews.

Reviewers who seek assistance from a trainee or colleague in the performance of a review should acknowledge these individuals' contributions in the written comments submitted to the editor. These individuals must maintain the confidentiality of the manuscript as outlined above.

Reviewers are expected to respond promptly to requests to review and to submit reviews within the time agreed. Reviewers' comments should be constructive, honest, and polite.

Reviewers should declare their relationships and activities that might bias their evaluation of a manuscript and recuse themselves from the peer-review process if a conflict exists.

\section{Journal Owners and Editorial Freedom 1. Journal Owners}

Owners and editors of medical journals share a common purpose, but they have different responsibilities, and sometimes those differences lead to conflicts.

It is the responsibility of medical journal owners to appoint and dismiss editors. Owners should provide editors at the time of their appointment with a contract that clearly states their rights and duties, authority, the general terms of their appointment, and mechanisms for resolving conflict. The editor's performance may be assessed using mutually agreed-upon measures, including but not necessarily limited to readership, manuscript submissions and handling times, and various journal metrics.

Owners should only dismiss editors for substantial reasons, such as scientific misconduct, disagreement with the long-term editorial direction of the journal, inadequate performance by agreed-upon performance metrics, or inappropriate behavior that is incompatible with a position of trust.

Appointments and dismissals should be based on evaluations by a panel of independent experts, rather than by a small number of executives of the owning organization. This is especially necessary in the case of dismissals because of the high value society places on freedom of speech within science and because it is often the responsibility of editors to challenge the status quo in ways that may conflict with the interests of the journal's owners.

A medical journal should explicitly state its governance and relationship to a journal owner (e.g., a sponsoring society).

\section{Editorial Freedom}

The ICMJE adopts the World Association of Medical Editors' definition of editorial freedom (http://wame.org/ editorial-independence), which holds that editors-inchief have full authority over the entire editorial content of their journal and the timing of publication of that content. Journal owners should not interfere in the evaluation, selection, scheduling, or editing of individual articles either directly or by creating an environment that 
Recommendations for the Conduct, Reporting, Editing, and Publication of Scholarly Work in Medical Journals

strongly influences decisions. Editors should base editorial decisions on the validity of the work and its importance to the journal's readers, not on the commercial implications for the journal, and editors should be free to express critical but responsible views about all aspects of medicine without fear of retribution, even if these views conflict with the commercial goals of the publisher.

Editors-in-chief should also have the final say in decisions about which advertisements or sponsored content, including supplements, the journal will and will not carry, and they should have final say in use of the journal brand and in overall policy regarding commercial use of journal content.

Journals are encouraged to establish an independent and diverse editorial advisory board to help the editor establish and maintain editorial policy. To support editorial decisions and potentially controversial expressions of opinion, owners should ensure that appropriate insurance is obtained in the event of legal action against the editors, and should ensure that legal advice is available when necessary. If legal problems arise, the editor should inform their legal adviser and their owner and/or publisher as soon as possible. Editors should defend the confidentiality of authors and peer reviewers (names and reviewer comments) in accordance with ICMJE policy (see Section II.C.2.a). Editors should take all reasonable steps to check the facts in journal commentary, including that in news sections and social media postings, and should ensure that staff working for the journal adhere to best journalistic practices including contemporaneous note-taking and seeking a response from all parties when possible before publication. Such practices in support of truth and public interest may be particularly relevant in defense against legal allegations of libel.

To secure editorial freedom in practice, the editor should have direct access to the highest level of ownership, not to a delegated manager or administrative officer.

Editors and editors' organizations are obliged to support the concept of editorial freedom and to draw major transgressions of such freedom to the attention of the international medical, academic, and lay communities.

\section{E. Protection of Research Participants}

All investigators should ensure that the planning, conduct, and reporting of human research are in accordance with the Helsinki Declaration as revised in 2013 (www.wma.net/policies-post/wma-declaration-of-helsinkiethical-principles-for-medical-research-involving-humansubjects/). All authors should seek approval to conduct research from an independent local, regional, or national review body (e.g., ethics committee, institutional review board). If doubt exists whether the research was conducted in accordance with the Helsinki Declaration, the authors must explain the rationale for their approach and demonstrate that the local, regional, or national review body explicitly approved the doubtful aspects of the study. Approval by a responsible review body does not preclude editors from forming their own judgment whether the conduct of the research was appropriate.
Patients have a right to privacy that should not be violated without informed consent. Identifying information, including names, initials, or hospital numbers, should not be published in written descriptions, photographs, or pedigrees unless the information is essential for scientific purposes and the patient (or parent or guardian) gives written informed consent for publication. Informed consent for this purpose requires that an identifiable patient be shown the manuscript to be published. Authors should disclose to these patients whether any potential identifiable material might be available via the Internet as well as in print after publication. Patient consent should be written and archived with the journal, the authors, or both, as dictated by local regulations or laws. Applicable laws vary from locale to locale, and journals should establish their own policies with legal guidance. Since a journal that archives the consent will be aware of patient identity, some journals may decide that patient confidentiality is better guarded by having the author archive the consent and instead providing the journal with a written statement that attests that they have received and archived written patient consent.

Nonessential identifying details should be omitted. Informed consent should be obtained if there is any doubt that anonymity can be maintained. For example, masking the eye region in photographs of patients is inadequate protection of anonymity. If identifying characteristics are deidentified, authors should provide assurance, and editors should so note, that such changes do not distort scientific meaning.

The requirement for informed consent should be included in the journal's instructions for authors. When informed consent has been obtained, it should be indicated in the published article.

When reporting experiments on animals, authors should indicate whether institutional and national standards for the care and use of laboratory animals were followed.

\section{Publishing and Editorial Issues Related to Publication in Medical JoURNALS}

\section{A. Corrections, Retractions, Republications, and Version Control}

Honest errors are a part of science and publishing and require publication of a correction when they are detected. Corrections are needed for errors of fact. Matters of debate are best handled as letters to the editor, as print or electronic correspondence, or as posts in a journal-sponsored online forum. Updates of previous publications (e.g., an updated systematic review or clinical guideline) are considered a new publication rather than a version of a previously published article.

If a correction is needed, journals should follow these minimum standards:

- The journal should publish a correction notice as soon as possible detailing changes from and citing the original publication; the correction should be on an electronic or numbered print page that is 
Recommendations for the Conduct, Reporting, Editing, and Publication of Scholarly Work in Medical Journals

included in an electronic or a print Table of Contents to ensure proper indexing.

- The journal should also post a new article version with details of the changes from the original version and the date(s) on which the changes were made.

- The journal should archive all prior versions of the article. This archive can be either directly accessible to readers or can be made available to the reader on request.

- Previous electronic versions should prominently note that there are more recent versions of the article.

- The citation should be to the most recent version.

Pervasive errors can result from a coding problem or a miscalculation and may result in extensive inaccuracies throughout an article. If such errors do not change the direction or significance of the results, interpretations, and conclusions of the article, a correction should be published that follows the minimum standards noted above.

Errors serious enough to invalidate a paper's results and conclusions may require retraction. However, retraction with republication (also referred to as "replacement") can be considered in cases where honest error (e.g., a misclassification or miscalculation) leads to a major change in the direction or significance of the results, interpretations, and conclusions. If the error is judged to be unintentional, the underlying science appears valid, and the changed version of the paper survives further review and editorial scrutiny, then retraction with republication of the changed paper, with an explanation, allows full correction of the scientific literature. In such cases, it is helpful to show the extent of the changes in supplementary material or in an appendix, for complete transparency.

\section{B. Scientific Misconduct, Expressions of Concern, and Retraction}

Scientific misconduct in research and non-research publications includes but is not necessarily limited to data fabrication; data falsification, including deceptive manipulation of images; purposeful failure to disclose relationships and activities; and plagiarism. Some people consider failure to publish the results of clinical trials and other human studies a form of scientific misconduct. While each of these practices is problematic, they are not equivalent. Each situation requires individual assessment by relevant stakeholders. When scientific misconduct is alleged, or concerns are otherwise raised about the conduct or integrity of work described in submitted or published papers, the editor should initiate appropriate procedures detailed by such committees as the Committee on Publication Ethics (COPE) (http://publicationethics.org/resources/flowcharts), consider informing the institutions and funders, and may choose to publish an expression of concern pending the outcomes of those procedures. If the procedures involve an investigation at the authors' institution, the editor should seek to discover the outcome of that investigation; notify readers of the outcome if appropriate; and if the investigation proves scientific misconduct, publish a retraction of the article. There may be circumstances in which no misconduct is proven, but an exchange of letters to the editor could be published to highlight matters of debate to readers.
Expressions of concern and retractions should not simply be a letter to the editor. Rather, they should be prominently labelled, appear on an electronic or numbered print page that is included in an electronic or a print Table of Contents to ensure proper indexing, and include in their heading the title of the original article. Online, the retraction and original article should be linked in both directions and the retracted article should be clearly labelled as retracted in all its forms (abstract, full text, PDF). Ideally, the authors of the retraction should be the same as those of the article, but if they are unwilling or unable the editor may under certain circumstances accept retractions by other responsible persons, or the editor may be the sole author of the retraction or expression of concern. The text of the retraction should explain why the article is being retracted and include a complete citation reference to that article.

Retracted articles should remain in the public domain and be clearly labelled as retracted.

The validity of previous work by the author of a fraudulent paper cannot be assumed. Editors may ask the author's institution to assure them of the validity of other work published in their journals, or they may retract it. If this is not done, editors may choose to publish an announcement expressing concern that the validity of previously published work is uncertain.

The integrity of research may also be compromised by inappropriate methodology that could lead to retraction.

See COPE flowcharts for further guidance on retractions and expressions of concern. See Section IV.A.1.g.i for guidance about avoiding referencing retracted articles.

\section{Copyright}

Journals should make clear the type of copyright under which work will be published, and if the journal retains copyright, should detail the journal's position on the transfer of copyright for all types of content, including audio, video, protocols, and data sets. Medical journals may ask authors to transfer copyright to the journal. Some journals require transfer of a publication license. Some journals do not require transfer of copyright and rely on such vehicles as Creative Commons licenses. The copyright status of articles in a given journal can vary: Some content cannot be copyrighted (e.g., articles written by employees of some governments in the course of their work). Editors may waive copyright on other content, and some content may be protected under other agreements.

\section{Overlapping Publications \\ 1. Duplicate Submission}

Authors should not submit the same manuscript, in the same or different languages, simultaneously to more than one journal. The rationale for this standard is the potential for disagreement when two (or more) journals claim the right to publish a manuscript that has been submitted simultaneously to more than one journal, and the possibility that two or more journals will unknowingly and unnecessarily undertake the work of peer review, edit the same manuscript, and publish the same article. 


\section{Recommendations for the Conduct, Reporting, Editing, and Publication of Scholarly Work in Medical Journals}

\section{Duplicate and Prior Publication}

Duplicate publication is publication of a paper that overlaps substantially with one already published, without clear, visible reference to the previous publication. Prior publication may include release of information in the public domain.

Readers of medical journals deserve to be able to trust that what they are reading is original unless there is a clear statement that the author and editor are intentionally republishing an article (which might be considered for historic or landmark papers, for example). The bases of this position are international copyright laws, ethical conduct, and cost-effective use of resources. Duplicate publication of original research is particularly problematic because it can result in inadvertent double-counting of data or inappropriate weighting of the results of a single study, which distorts the available evidence.

When authors submit a manuscript reporting work that has already been reported in large part in a published article or is contained in or closely related to another paper that has been submitted or accepted for publication elsewhere, the letter of submission should clearly say so and the authors should provide copies of the related material to help the editor decide how to handle the submission. See also Section IV.B.

This recommendation does not prevent a journal from considering a complete report that follows publication of a preliminary report, such as a letter to the editor, a preprint, or an abstract or poster displayed at a scientific meeting. The ICMJE does not consider results or data contained in assessment reports published by health technology assessment agencies, medical regulators, medical device regulators, or other regulatory agencies to be duplicate publication. It also does not prevent journals from considering a paper that has been presented at a scientific meeting but was not published in full, or that is being considered for publication in proceedings or similar format. Press reports of scheduled meetings are not usually regarded as breaches of this rule, but they may be if additional data tables or figures enrich such reports. Authors should also consider how dissemination of their findings outside of scientific presentations at meetings may diminish the priority journal editors assign to their work.

Authors who choose to post their work on a preprint server should choose one that clearly identifies preprints as not peer-reviewed work and includes disclosures of authors' relationships and activities. It is the author's responsibility to inform a journal if the work has been previously posted on a preprint server. In addition, it is the author's (and not the journal editors') responsibility to ensure that preprints are amended to point readers to subsequent versions, including the final published article. See Section III.D.3.

In the event of a public health emergency (as defined by public health officials), information with immediate implications for public health should be disseminated without concern that this will preclude subsequent consideration for publication in a journal. We encourage editors to give priority to authors who have made crucial data publicly available without delay.
Sharing with public media, government agencies, or manufacturers the scientific information described in a paper or a letter to the editor that has been accepted but not yet published violates the policies of many journals. Such reporting may be warranted when the paper or letter describes major therapeutic advances; reportable diseases; or public health hazards, such as serious adverse effects of drugs, vaccines, other biological products, medical devices. This reporting, whether in print or online, should not jeopardize publication, but should be discussed with and agreed upon by the editor in advance when possible.

The ICMJE will not consider as prior publication the posting of trial results in any registry that meets the criteria noted in Section III.L if results are limited to a brief (500 word) structured abstract or tables (to include participants enrolled, key outcomes, and adverse events). The ICMJE encourages authors to include a statement with the registration that indicates that the results have not yet been published in a peer-reviewed journal, and to update the results registry with the full journal citation when the results are published.

Editors of different journals may together decide to simultaneously or jointly publish an article if they believe that doing so would be in the best interest of public health. However, the National Library of Medicine (NLM) indexes all such simultaneously published joint publications separately, so editors should include a statement making the simultaneous publication clear to readers.

Authors who attempt duplicate publication without such notification should expect at least prompt rejection of the submitted manuscript. If the editor was not aware of the violations and the article has already been published, then the article might warrant retraction with or without the author's explanation or approval.

See COPE flowcharts for further guidance on handling duplicate publication.

\section{Preprints}

Posting of work as a preprint may influence a journal's interest in or priority for peer review and publication of that work. Journals should clearly describe their policies related to the posting and citing of preprints in their Information for Authors. Authors should become familiar with the policies of journals they wish to submit their work to prior to posting work on a preprint server.

\section{a. Choosing a Preprint Archive}

There has been an increase in preprint archives in biomedicine. There are both benefits and harms in dissemination of scientific findings prior to peer review. To maximize potential benefits and minimize potential harms, authors who wish to make preprints of non-peerreviewed work publicly available should choose preprint archives that have the following characteristics:

- Clearly identify preprints as work that is not peer reviewed;

- Require authors to document disclosures of interest;

- Require authors to indicate funding source(s); 
Recommendations for the Conduct, Reporting, Editing, and Publication of Scholarly Work in Medical Journals

- Have a clear process for preprint archive users to notify archive administrators about concerns related to posted preprints-a public commenting feature is desirable for this purpose;

- Maintain metadata for preprints that are withdrawn from posting and post withdrawal notices indicating the timing and reason for withdrawal of a preprint; and

- Have a mechanism for authors to indicate when the preprint article has been subsequently published in a peer-reviewed journal.

\section{b. Submitting Manuscripts That Are in Preprint Arch- ives to a Peer-Reviewed Journal}

Authors should inform a journal if the work submitted to the journal has been posted on a preprint server and provide a link to the preprint, whether the posting occurs prior to submission or during the peer-review process. It is also helpful to indicate in the text of the manuscript, perhaps in the introduction, that a preprint is available and how reviewers can access that preprint. In addition, it is the authors' (and not the journal editors') responsibility to ensure that preprints are amended to point readers to subsequent versions of the work, including the published article. Authors should not post in the preprint archive the published article nor interim versions that are produced during the peer-review process that incorporate revisions based on journal feedback.

\section{c. Referencing Preprints in Submitted Manuscripts}

When preprints are cited in submitted manuscripts or published articles, the citation should clearly indicate that the reference is a preprint. When a preprint article has been subsequently published in a peer-reviewed journal, authors should cite the subsequent published article rather than the preprint article whenever appropriate. Journals should include the word "preprint" following the citation information in the reference list and consider indicating that the cited material is a preprint in the text. The citation should include the link to the preprint and DOI if the preprint archive issues DOls. Authors should be cautious about referencing preprints that were posted and never subsequently published in a peer-reviewed journal, but the time interval of concern will vary depending on the topic and specific reasons for citation.

\section{Acceptable Secondary Publication}

Secondary publication of material published in other journals or online may be justifiable and beneficial, especially when intended to disseminate important information to the widest possible audience (e.g., guidelines produced by government agencies and professional organizations in the same or a different language). Secondary publication for various other reasons may also be justifiable provided the following conditions are met:

1. The authors have received approval from the editors of both journals (the editor concerned with secondary publication must have access to the primary version).
2. The priority of the primary publication is respected by a publication interval negotiated by both editors with the authors.

3. The paper for secondary publication is intended for a different group of readers; an abbreviated version could be sufficient.

4. The secondary version faithfully reflects the authors, data, and interpretations of the primary version.

5. The secondary version informs readers, peers, and documenting agencies that the paper has been published in whole or in part elsewhere-for example, with a note that might read, "This article is based on a study first reported in the [journal title, with full reference]"-and the secondary version cites the primary reference.

6. The title of the secondary publication should indicate that it is a secondary publication (complete or abridged republication or translation) of a primary publication. Of note, the NLM does not consider translations to be "republications" and does not cite or index them when the original article was published in a journal that is indexed in MEDLINE.

When the same journal simultaneously publishes an article in multiple languages, the MEDLINE citation will note the multiple languages (e.g., Angelo M. Journal networking in nursing: a challenge to be shared. Rev Esc Enferm USP. 2011 Dec 45[6]:1281-2,1279-80,1283-4. Article in English, Portuguese, and Spanish. No abstract available. PMID: 22241182).

\section{Manuscripts Based on the Same Database}

If editors receive manuscripts from separate research groups or from the same group analyzing the same data set (e.g., from a public database, or systematic reviews or meta-analyses of the same evidence), the manuscripts should be considered independently because they may differ in their analytic methods, conclusions, or both. If the data interpretation and conclusions are similar, it may be reasonable although not mandatory for editors to give preference to the manuscript submitted first. Editors might consider publishing more than one manuscript that overlap in this way because different analytical approaches may be complementary and equally valid, but manuscripts based upon the same data set should add substantially to each other to warrant consideration for publication as separate papers, with appropriate citation of previous publications from the same data set to allow for transparency.

Secondary analyses of clinical trial data should cite any primary publication, clearly state that it contains secondary analyses/results, and use the same identifying trial registration number as the primary trial and unique, persistent data set identifier.

Sometimes for large trials it is planned from the beginning to produce numerous separate publications regarding separate research questions but using the same original participant sample. In this case authors may use the original single trial registration number, if all the outcome parameters were defined in the original registration. If the authors registered several substudies as separate entries in, for example, ClinicalTrials.gov, 
Recommendations for the Conduct, Reporting, Editing, and Publication of Scholarly Work in Medical Journals

then the unique trial identifier should be given for the study in question. The main issue is transparency, so no matter what model is used it should be obvious for the reader.

\section{E. Correspondence}

Medical journals should provide readers with a mechanism for submitting comments, questions, or criticisms about published articles, usually but not necessarily always through a correspondence section or online forum. The authors of articles discussed in correspondence or an online forum have a responsibility to respond to substantial criticisms of their work using those same mechanisms and should be asked by editors to respond. Authors of correspondence should be asked to declare any competing relationships or activities.

Correspondence may be edited for length, grammatical correctness, and journal style. Alternatively, editors may choose to make available to readers unedited correspondence, for example, via an online commenting system. Such commenting is not indexed in MEDLINE unless it is subsequently published on a numbered electronic or print page. However the journal handles correspondence, it should make known its practice. In all instances, editors must make an effort to screen discourteous, inaccurate, or libellous comments.

Responsible debate, critique, and disagreement are important features of science, and journal editors should encourage such discourse ideally within their own journals about the material they have published. Editors, however, have the prerogative to reject correspondence that is irrelevant, uninteresting, or lacking cogency, but they also have a responsibility to allow a range of opinions to be expressed and to promote debate.

In the interests of fairness and to keep correspondence within manageable proportions, journals may want to set time limits for responding to published material and for debate on a given topic.

\section{F. Fees}

Journals should be transparent about their types of revenue streams. Any fees or charges that are required for manuscript processing and/or publishing materials in the journal shall be clearly stated in a place that is easy for potential authors to find prior to submitting their manuscripts for review or explained to authors before they begin preparing their manuscript for submission (http://publicationethics.org/files/u7140 /Principles_of_Transparency_and_Best_Practice_in_Scholarly_ Publishing.pdf).

\section{G. Supplements, Theme Issues, and Special Series}

Supplements are collections of papers that deal with related issues or topics, are published as a separate issue of the journal or as part of a regular issue, and may be funded by sources other than the journal's publisher. Because funding sources can bias the content of supplements through the choice of topics and viewpoints, journals should adopt the following principles, which also apply to theme issues or special series that have external funding and/or guest editors:
1. The journal editor must be given and must take full responsibility for the policies, practices, and content of supplements, including complete control of the decision to select authors, peer reviewers, and content for the supplement. Editing by the funding organization should not be permitted.

2. The journal editor has the right to appoint one or more external editors of the supplement and must take responsibility for the work of those editors.

3. The journal editor must retain the authority to send supplement manuscripts for external peer review and to reject manuscripts submitted for the supplement with or without external review. These conditions should be made known to authors and any external editors of the supplement before beginning editorial work on it.

4. The source of the idea for the supplement, sources of funding for the supplement's research and publication, and products of the funding source related to content considered in the supplement should be clearly stated in the introductory material.

5. Advertising in supplements should follow the same policies as those of the primary journal.

6. Journal editors must enable readers to distinguish readily between ordinary editorial pages and supplement pages.

7. Journal and supplement editors must not accept personal favors or direct remuneration from sponsors of supplements.

8. Secondary publication in supplements (republication of papers published elsewhere) should be clearly identified by the citation of the original paper and by the title.

9. The same principles of authorship and disclosure of relationships and activities discussed elsewhere in this document should be applied to supplements.

\section{H. Sponsorship or Partnership}

Various entities may seek interactions with journals or editors in the form of sponsorships, partnerships, meetings, or other types of activities. To preserve editorial independence, these interactions should be governed by the same principles outlined above for Supplements, Theme Issues, and Special Series (Section III.G).

\section{Electronic Publishing}

Most medical journals are now published in electronic as well as print versions, and some are published only in electronic form. Principles of print and electronic publishing are identical, and the recommendations of this document apply equally to both. However, electronic publishing provides opportunities for versioning and raises issues about link stability and content preservation that are addressed here.

Recommendations for corrections and versioning are detailed in Section III.A.

Electronic publishing allows linking to sites and resources beyond journals over which journal editors have no editorial control. For this reason, and because links to external sites could be perceived as implying 
Recommendations for the Conduct, Reporting, Editing, and Publication of Scholarly Work in Medical Journals

endorsement of those sites, journals should be cautious about external linking. When a journal does link to an external site, it should state that it does not endorse or take responsibility or liability for any content, advertising, products, or other materials on the linked sites, and does not take responsibility for the sites' availability.

Permanent preservation of journal articles on a journal's website, or in an independent archive or a credible repository, is essential for the historical record. Removing an article from a journal's website in its entirety is almost never justified as copies of the article may have been downloaded even if its online posting was brief. Such archives should be freely accessible or accessible to archive members. Deposition in multiple archives is encouraged. However, if necessary for legal reasons (e.g., libel action), the URL for the removed article must contain a detailed reason for the removal, and the article must be retained in the journal's internal archive.

Permanent preservation of a journal's total content is the responsibility of the journal publisher, who in the event of journal termination should be certain the journal files are transferred to a responsible third party who can make the content available.

Journal websites should post the date that nonarticle web pages, such as those listing journal staff, editorial board members, and instructions for authors, were last updated.

\section{J. Advertising}

Most medical journals carry advertising, which generates income for their publishers, but journals should not be dominated by advertisements, and advertising must not be allowed to influence editorial decisions.

Journals should have formal, explicit, written policies for advertising in both print and electronic versions. Best practice prohibits selling advertisements intended to be juxtaposed with editorial content on the same product. Advertisements should be clearly identifiable as advertisements. Editors should have full and final authority for approving print and online advertisements and for enforcing advertising policy.

Journals should not carry advertisements for products proven to be seriously harmful to health. Editors should ensure that existing regulatory or industry standards for advertisements specific to their country are enforced, or develop their own standards. The interests of organizations or agencies should not control classified and other nondisplay advertising, except where required by law. Editors should consider all criticisms of advertisements for publication.

\section{K. Journals and the Media}

Journals' interactions with media should balance competing priorities. The general public has a legitimate interest in all journal content and is entitled to important information within a reasonable amount of time, and editors have a responsibility to facilitate that. However, media reports of scientific research before it has been peer-reviewed and fully vetted may lead to dissemination of inaccurate or premature conclusions, and doctors in practice need to have research reports available in full detail before they can advise patients about the reports' conclusions.

An embargo system has been established in some countries and by some journals to assist this balance, and to prevent publication of stories in the general media before publication of the original research in the journal. For the media, the embargo creates a "level playing field," which most reporters and writers appreciate since it minimizes the pressure on them to publish stories before competitors when they have not had time to prepare carefully. Consistency in the timing of public release of biomedical information is also important in minimizing economic chaos, since some articles contain information that has potential to influence financial markets. The ICMJE acknowledges criticisms of embargo systems as being self-serving of journals' interests and an impediment to rapid dissemination of scientific information, but believes the benefits of the systems outweigh their harms.

The following principles apply equally to print and electronic publishing and may be useful to editors as they seek to establish policies on interactions with the media:

- Editors can foster the orderly transmission of medical information from researchers, through peer-reviewed journals, to the public. This can be accomplished by an agreement with authors that they will not publicize their work while their manuscript is under consideration or awaiting publication and an agreement with the media that they will not release stories before publication of the original research in the journal, in return for which the journal will cooperate with them in preparing accurate stories by issuing, for example, a press release.

- Editors need to keep in mind that an embargo system works on the honor system-no formal enforcement or policing mechanism exists. The decision of a significant number of media outlets or biomedical journals not to respect the embargo system would lead to its rapid dissolution.

- Notwithstanding authors' belief in their work, very little medical research has such clear and urgently important clinical implications for the public's health that the news must be released before full publication in a journal. When such exceptional circumstances occur, the appropriate authorities responsible for public health should decide whether to disseminate information to physicians and the media in advance and should be responsible for this decision. If the author and the appropriate authorities wish to have a manuscript considered by a particular journal, the editor should be consulted before any public release. If editors acknowledge the need for immediate release, they should waive their policies limiting prepublication publicity.

- Policies designed to limit prepublication publicity should not apply to accounts in the media of presentations at scientific meetings or to the abstracts from 


\section{Recommendations for the Conduct, Reporting, Editing, and Publication of Scholarly Work in Medical Journals}

these meetings (see Duplicate Publication). Researchers who present their work at a scientific meeting should feel free to discuss their presentations with reporters but should be discouraged from offering more detail about their study than was presented in the talk, or should consider how giving such detail might diminish the priority journal editors assign to their work (see Duplicate Publication).

- When an article is close to being published, editors or journal staff should help the media prepare accurate reports by providing news releases, answering questions, supplying advance copies of the article, or referring reporters to appropriate experts. This assistance should be contingent on the media's cooperation in timing the release of a story to coincide with publication of the article.

\section{Clinical Trials \\ 1. Registration}

The ICMJE's clinical trial registration policy is detailed in a series of editorials (see News and Editorials [www.icmje.org/news-and-editorials/] and FAQs [www. icmje.org/about-icmje/faqs/]).

Briefly, the ICMJE requires, and recommends that all medical journal editors require, registration of clinical trials in a public trials registry at or before the time of first patient enrollment as a condition of consideration for publication. Editors requesting inclusion of their journal on the ICMJE website list of publications that follow ICMJE guidance (www.icmje.org/journals.html) should recognize that the listing implies enforcement by the journal of ICMJE's trial registration policy.

ICMJE uses the date trial registration materials were first submitted to a registry as the date of registration. When there is a substantial delay between the submission of registration materials and their posting at the trial registry, editors may inquire about the circumstances that led to the delay.

The ICMJE defines a clinical trial as any research project that prospectively assigns people or a group of people to an intervention, with or without concurrent comparison or control groups, to study the relationship between a health-related intervention and a health outcome. Health-related interventions are those used to modify a biomedical or health-related outcome; examples include drugs, surgical procedures, devices, behavioral treatments, educational programs, dietary interventions, quality improvement interventions, and process-of-care changes. Health outcomes are any biomedical or health-related measures obtained in patients or participants, including pharmacokinetic measures and adverse events. The ICMJE does not define the timing of first participant enrollment, but best practice dictates registration by the time of first participant consent.

The ICMJE accepts publicly accessible registration in any registry that is a primary register of the $\mathrm{WHO}$ International Clinical Trials Registry Platform (ICTRP) (www.who.int/clinical-trials-registry-platform/network/whodata-set) that includes the minimum acceptable 24-item trial registration data set or in ClinicalTrials.gov, which is a data provider to the WHO ICTRP. The ICMJE endorses these registries because they meet several criteria. They are accessible to the public at no charge, open to all prospective registrants, managed by a not-for-profit organization, have a mechanism to ensure the validity of the registration data, and are electronically searchable. An acceptable registry must include the minimum 24-item trial registration data set (http://prsinfo.clinicaltrials.gov/ trainTrainer/WHO-ICMJE-ClinTrialsgov-Cross-Ref.pdf or www.who.int/clinical-trials-registry-platform) at the time of registration and before enrollment of the first participant.

The ICMJE considers inadequate trial registrations missing any of the 24 data fields, those that have fields that contain uninformative information, or registrations that are not made publicly accessible such as phase I trials submitted to the EU-CTR and trials of devices for which the information is placed in a "lock box." In order to comply with ICMJE policy, investigators registering trials of devices at ClinicalTrials.gov must "opt out" of the lock box by electing public posting prior to device approval. Approval to conduct a study from an independent local, regional, or national review body (e.g., ethics committee, institutional review board) does not fulfill the ICMJE requirement for prospective clinical trial registration. Although not a required item, the ICMJE encourages authors to include a statement that indicates that the results have not yet been published in a peerreviewed journal, and to update the registration with the full journal citation when the results are published.

The purpose of clinical trial registration is to prevent selective publication and selective reporting of research outcomes, to prevent unnecessary duplication of research effort, to help patients and the public know what trials are planned or ongoing into which they might want to enroll, and to help give ethics review boards considering approval of new studies a view of similar work and data relevant to the research they are considering. Retrospective registration, for example at the time of manuscript submission, meets none of these purposes. Those purposes apply also to research with alternative designs, for example observational studies. For that reason, the ICMJE encourages registration of research with non-trial designs, but because the exposure or intervention in non-trial research is not dictated by the researchers, the ICMJE does not require it.

Secondary data analyses of primary (parent) clinical trials should not be registered as separate clinical trials, but instead should reference the trial registration number of the primary trial.

The ICMJE expects authors to ensure that they have met the requirements of their funding and regulatory agencies regarding aggregate clinical trial results reporting in clinical trial registries. It is the authors', and not the journal editors', responsibility to explain any discrepancies between results reported in registries and journal publications. The ICMJE will not consider as prior publication the posting of trial results in any registry that meets the above criteria if results are limited to a brief (500 word) structured abstract or tables (to include trial 
Recommendations for the Conduct, Reporting, Editing, and Publication of Scholarly Work in Medical Journals

participants enrolled, baseline characteristics, primary and secondary outcomes, and adverse events).

The ICMJE recommends that journals publish the trial registration number at the end of the abstract. The ICMJE also recommends that, whenever a registration number is available, authors list this number the first time they use a trial acronym to refer either to the trial they are reporting or to other trials that they mention in the manuscript.

Editors may consider whether the circumstances involved in a failure to appropriately register a clinical trial were likely to have been intended to or resulted in biased reporting. Because of the importance of prospective trial registration, if an exception to this policy is made, trials must be registered and the authors should indicate in the publication when registration was completed and why it was delayed. Editors should publish a statement indicating why an exception was allowed. The ICMJE emphasizes that such exceptions should be rare, and that authors failing to prospectively register a trial risk its inadmissibililty to our journals.

\section{Data Sharing}

The ICMJE's data sharing statement policy is detailed in an editorial (see Updates and Editorials [www.icmje.org/update.html]).

1. As of 1 July 2018 manuscripts submitted to ICMJE journals that report the results of clinical trials must contain a data sharing statement as described below.

2. Clinical trials that begin enrolling participants on or after 1 January 2019 must include a data sharing plan in the trial's registration. The ICMJE's policy regarding trial registration is explained at www.icmje.org/ recommendations/browse/publishing-and-editorialissues/clinical-trial-registration.html. If the data sharing plan changes after registration this should be reflected in the statement submitted and published with the manuscript, and updated in the registry record.

Data sharing statements must indicate the following: whether individual deidentified participant data (including data dictionaries) will be shared ("undecided" is not an acceptable answer); what data in particular will be shared; whether additional, related documents will be available (e.g., study protocol, statistical analysis plan, etc.); when the data will become available and for how long; by what access criteria data will be shared (including with whom, for what types of analyses, and by what mechanism). Illustrative examples of data sharing statements that would meet these requirements are provided in Table 1.

Authors of secondary analyses using shared data must attest that their use was in accordance with the terms (if any) agreed to upon their receipt. They must also reference the source of the data using its unique, persistent identifier to provide appropriate credit to those who generated it and allow searching for the studies it has supported. Authors of secondary analyses must explain completely how theirs differ from previous analyses. In addition, those who generate and then share clinical trial data sets deserve substantial credit for their efforts. Those using data collected by others should seek collaboration with those who collected the data. As collaboration will not always be possible, practical, or desired, the efforts of those who generated the data must be recognized.

\section{Manuscript Preparation and Submission}

\section{A. Preparing a Manuscript for Submission to a Medical Journal \\ 1. General Principles}

The text of articles reporting original research is usually divided into Introduction, Methods, Results, and Discussion sections. This so-called "IMRAD" structure is not an arbitrary publication format but a reflection of the process of scientific discovery. Articles often need subheadings within these sections to further organize their content. Other types of articles, such as meta-analyses, may require different formats, while case reports, narrative reviews, and editorials may have less structured or unstructured formats.

Electronic formats have created opportunities for adding details or sections, layering information, crosslinking, or extracting portions of articles in electronic versions. Supplementary electronic-only material should be submitted and sent for peer review simultaneously with the primary manuscript.

\section{Reporting Guidelines}

Reporting guidelines have been developed for different study designs; examples include CONSORT (www. consort-statement.org) for randomized trials, STROBE for observational studies (http://strobe-statement.org/), PRISMA for systematic reviews and meta-analyses (http://prisma-statement.org/), and STARD for studies of diagnostic accuracy (http://www.equator-network.org/ reporting-guidelines/stard/). Journals are encouraged to ask authors to follow these guidelines because they help authors describe the study in enough detail for it to be evaluated by editors, reviewers, readers, and other researchers evaluating the medical literature. Authors of review manuscripts are encouraged to describe the methods used for locating, selecting, extracting, and synthesizing data; this is mandatory for systematic reviews. Good sources for reporting guidelines are the EQUATOR Network (www.equator-network.org/home/) and the NLM's Research Reporting Guidelines and Initiatives (www.nlm.nih.gov/services/research_report_guide.html).

\section{Manuscript Sections}

The following are general requirements for reporting within sections of all study designs and manuscript formats.

\section{a. Title Page}

General information about an article and its authors is presented on a manuscript title page and usually includes the article title, author information, any disclaimers, sources of support, word count, and sometimes the number of tables and figures. 


\section{Unauthorized reproduction of this article is prohibited}

Recommendations for the Conduct, Reporting, Editing, and Publication of Scholarly Work in Medical Journals

\begin{tabular}{|c|c|c|c|c|}
\hline & Example 1 & Example 2 & Example 3 & Example 4 \\
\hline $\begin{array}{l}\text { Will individual participant } \\
\text { data be available } \\
\text { (including data } \\
\text { dictionaries)? }\end{array}$ & Yes & Yes & Yes & No \\
\hline $\begin{array}{l}\text { What data in particular } \\
\text { will be shared? }\end{array}$ & $\begin{array}{l}\text { All of the individual participant } \\
\text { data collected during the } \\
\text { trial, after deidentification. }\end{array}$ & $\begin{array}{l}\text { Individual participant data that } \\
\text { underlie the results reported } \\
\text { in this article, after deidenti- } \\
\text { fication (text, tables, figures, } \\
\text { and appendices). }\end{array}$ & $\begin{array}{l}\text { Individual participant data that } \\
\text { underlie the results reported } \\
\text { in this article, after deidenti- } \\
\text { fication (text, tables, figures, } \\
\text { and appendices). }\end{array}$ & Not available \\
\hline $\begin{array}{l}\text { What other documents } \\
\text { will be available? }\end{array}$ & $\begin{array}{l}\text { Study Protocol, Statistical } \\
\text { Analysis Plan, Informed } \\
\text { Consent Form, Clinical } \\
\text { Study Report, Analytic Code }\end{array}$ & $\begin{array}{l}\text { Study Protocol, Statistical } \\
\text { Analysis Plan, Analytic Code }\end{array}$ & Study Protocol & Not available \\
\hline $\begin{array}{l}\text { When will data be avail- } \\
\text { able (start and end } \\
\text { dates)? }\end{array}$ & $\begin{array}{l}\text { Immediately following publica- } \\
\text { tion. No end date. }\end{array}$ & $\begin{array}{l}\text { Beginning } 3 \text { months and end- } \\
\text { ing } 5 \text { years following article } \\
\text { publication. }\end{array}$ & $\begin{array}{l}\text { Beginning } 9 \text { months and end- } \\
\text { ing } 36 \text { months following arti- } \\
\text { cle publication. }\end{array}$ & Not applicable \\
\hline With whom? & $\begin{array}{l}\text { Anyone who wishes to access } \\
\text { the data. }\end{array}$ & $\begin{array}{l}\text { Researchers who provide a } \\
\text { methodologically sound } \\
\text { proposal. }\end{array}$ & $\begin{array}{l}\text { Investigators whose proposed } \\
\text { use of the data has been } \\
\text { approved by an independ- } \\
\text { ent review committee } \\
\text { (learned intermediary) iden- } \\
\text { tified for this purpose. }\end{array}$ & Not applicable \\
\hline $\begin{array}{l}\text { For what types of } \\
\text { analyses? }\end{array}$ & Any purpose. & $\begin{array}{l}\text { To achieve aims in the } \\
\text { approved proposal. }\end{array}$ & $\begin{array}{l}\text { For individual participant data } \\
\text { meta-analysis. }\end{array}$ & Not applicable \\
\hline $\begin{array}{l}\text { By what mechanism will } \\
\text { data be made } \\
\text { available? }\end{array}$ & $\begin{array}{l}\text { Data are available indefinitely } \\
\text { at (Link to be included). }\end{array}$ & $\begin{array}{l}\text { Proposals should be directed } \\
\text { to xxx@yyy. } \\
\text { To gain access, data reques- } \\
\text { tors will need to sign a data } \\
\text { access agreement. Data are } \\
\text { available for } 5 \text { years at a } \\
\text { third-party website (Link to } \\
\text { be included). }\end{array}$ & $\begin{array}{l}\text { Proposals may be submitted } \\
\text { up to } 36 \text { months following } \\
\text { article publication. After } 36 \\
\text { months the data will be } \\
\text { available in our University's } \\
\text { data warehouse but without } \\
\text { investigator support other } \\
\text { than deposited metadata. } \\
\text { Information regarding sub- } \\
\text { mitting proposals and } \\
\text { accessing data may be } \\
\text { found at (Link to be } \\
\text { provided). }\end{array}$ & Not applicable \\
\hline
\end{tabular}

*These examples are meant to illustrate a range of, but not all, data sharing options.

Article title. The title provides a distilled description of the complete article and should include information that, along with the abstract, will make electronic retrieval of the article sensitive and specific. Reporting guidelines recommend and some journals require that information about the study design be a part of the title (particularly important for randomized trials and systematic reviews and meta-analyses). Some journals require a short title, usually no more than 40 characters (including letters and spaces) on the title page or as a separate entry in an electronic submission system. Electronic submission systems may restrict the number of characters in the title.

Author information. Each author's highest academic degrees should be listed, although some journals do not publish these. The name of the department(s) and institution(s) or organizations where the work should be attributed should be specified. Most electronic submission systems require that authors provide full contact information, including land mail and e-mail addresses, but the title page should list the corresponding authors' telephone and fax numbers and e-mail address. ICMJE encourages the listing of authors' Open Researcher and Contributor Identification (ORCID).
Disclaimers. An example of a disclaimer is an author's statement that the views expressed in the submitted article are his or her own and not an official position of the institution or funder.

Source(s) of support. These include grants, equipment, drugs, and/or other support that facilitated conduct of the work described in the article or the writing of the article itself. Inappropriate attribution of funding sources and affiliations are misleading and should be avoided.

Word count. A word count for the paper's text, excluding its abstract, acknowledgments, tables, figure legends, and references, allows editors and reviewers to assess whether the information contained in the paper warrants the paper's length, and whether the submitted manuscript fits within the journal's formats and word limits. A separate word count for the abstract is useful for the same reason.

Number of figures and tables. Some submission systems require specification of the number of figures and tables before uploading the relevant files. These numbers allow editorial staff and reviewers to confirm that all figures and tables were actually included with the manuscript and, because tables and figures occupy space, to assess if the information provided by the figures and 
Recommendations for the Conduct, Reporting, Editing, and Publication of Scholarly Work in Medical Journals

tables warrants the paper's length and if the manuscript fits within the journal's space limits.

Disclosure of relationships and activities. Disclosure information for each author needs to be part of the manuscript; each journal should develop standards with regard to the form the information should take and where it will be posted. The ICMJE has developed a uniform Disclosure Form for use by ICMJE member journals (www.icmje.org/coi_disclosure.pdf), and the ICMJE encourages other journals to adopt it. Despite availability of the form, editors may require disclosure of relationships and activities on the manuscript title page or other Disclosure section in the manuscript to save the work of collecting forms from each author prior to making an editorial decision or to save reviewers and readers the work of reading each author's form.

\section{b. Abstract}

Original research, systematic reviews, and metaanalyses require structured abstracts. The abstract should provide the context or background for the study and should state the study's purpose, basic procedures (selection of study participants, settings, measurements, analytical methods), main findings (giving specific effect sizes and their statistical and clinical significance, if possible), and principal conclusions. It should emphasize new and important aspects of the study or observations, note important limitations, and not overinterpret findings. Clinical trial abstracts should include items that the CONSORT group has identified as essential (www. consort-statement.org/resources/downloads/

extensions/consort-extension-for-abstracts-2008pdf/).

Funding sources should be listed separately after the abstract to facilitate proper display and indexing for search retrieval by MEDLINE.

Because abstracts are the only substantive portion of the article indexed in many electronic databases, and the only portion many readers read, authors need to ensure that they accurately reflect the content of the article. Unfortunately, information in abstracts often differs from that in the text. Authors and editors should work in the process of revision and review to ensure that information is consistent in both places. The format required for structured abstracts differs from journal to journal, and some journals use more than one format; authors need to prepare their abstracts in the format specified by the journal they have chosen.

The ICMJE recommends that journals publish the clinical trial registration number at the end of the abstract. The ICMJE also recommends that, when a registration number is available, authors list that number the first time they use a trial acronym to refer to the trial they are reporting or to other trials that they mention in the manuscript. If the data have been deposited in a public repository and/or are being used in a secondary analysis, authors should state at the end of the abstract the unique, persistent data set identifier; repository name; and number.

\section{c. Introduction}

Provide a context or background for the study (that is, the nature of the problem and its significance). State the specific purpose or research objective of, or hypothesis tested by, the study or observation. Cite only directly pertinent references, and do not include data or conclusions from the work being reported.

\section{d. Methods}

The guiding principle of the Methods section should be clarity about how and why a study was done in a particular way. The Methods section should aim to be sufficiently detailed such that others with access to the data would be able to reproduce the results. In general, the section should include only information that was available at the time the plan or protocol for the study was being written; all information obtained during the study belongs in the Results section. If an organization was paid or otherwise contracted to help conduct the research (examples include data collection and management), then this should be detailed in the methods.

The Methods section should include a statement indicating that the research was approved by an independent local, regional or national review body (e.g., ethics committee, institutional review board). If doubt exists whether the research was conducted in accordance with the Helsinki Declaration, the authors must explain the rationale for their approach and demonstrate that the local, regional or national review body explicitly approved the doubtful aspects of the study. See Section II.E.

\section{i. Selection and Description of Participants}

Clearly describe the selection of observational or experimental participants (healthy individuals or patients, including controls), including eligibility and exclusion criteria and a description of the source population. Because the relevance of such variables as age, sex, or ethnicity is not always known at the time of study design, researchers should aim for inclusion of representative populations into all study types and at a minimum provide descriptive data for these and other relevant demographic variables. Comment on how representative the study sample is of the larger population of interest.

Ensure correct use of the terms sex (when reporting biological factors) and gender (identity, psychosocial or cultural factors), and, unless inappropriate, report the sex and/or gender of study participants, the sex of animals or cells, and describe the methods used to determine sex and gender. If the study was done involving an exclusive population, for example in only one sex, authors should justify why, except in obvious cases (e.g., prostate cancer). Authors should define how they determined race or ethnicity and justify their relevance. In the case where race or ethnicity was not collected, explain why it was not collected. Race and ethnicity are social and not biological constructs; authors should interpret results associated with race and ethnicity in that context. Authors should use neutral, precise, and respectful language to describe study participants and avoid the use of terminology that might stigmatize participants.

\section{ii. Technical Information}

Specify the study's main and secondary objectivesusually identified as primary and secondary outcomes. Identify methods, equipment (give the manufacturer's name and address in parentheses), and procedures in sufficient detail to allow others to reproduce the results. Give references to established methods, including 


\section{Recommendations for the Conduct, Reporting, Editing, and Publication of Scholarly Work in Medical Journals}

statistical methods (see below); provide references and brief descriptions for methods that have been published but are not well-known; describe new or substantially modified methods, give the reasons for using them, and evaluate their limitations. Identify precisely all drugs and chemicals used, including generic name(s), dose(s), and route(s) of administration. Identify appropriate scientific names and gene names.

\section{iii. Statistics}

Describe statistical methods with enough detail to enable a knowledgeable reader with access to the original data to judge its appropriateness for the study and to verify the reported results. When possible, quantify findings and present them with appropriate indicators of measurement error or uncertainty (such as confidence intervals). Avoid relying solely on statistical hypothesis testing, such as $P$ values, which fail to convey important information about effect size and precision of estimates. References for the design of the study and statistical methods should be to standard works when possible (with pages stated). Define statistical terms, abbreviations, and most symbols. Specify the statistical software package(s) and versions used. Distinguish prespecified from exploratory analyses, including subgroup analyses.

\section{e. Results}

Present your results in logical sequence in the text, tables, and figures, giving the main or most important findings first. Do not repeat all the data in the tables or figures in the text; emphasize or summarize only the most important observations. Provide data on all primary and secondary outcomes identified in the Methods section. Extra or supplementary materials and technical details can be placed in an appendix where they will be accessible but will not interrupt the flow of the text, or they can be published solely in the electronic version of the journal.

Give numeric results not only as derivatives (e.g., percentages) but also as the absolute numbers from which the derivatives were calculated. Restrict tables and figures to those needed to explain the argument of the paper and to assess supporting data. Use graphs as an alternative to tables with many entries; do not duplicate data in graphs and tables. Avoid nontechnical uses of technical terms in statistics, such as "random" (which implies a randomizing device), "normal," "significant," "correlations," and "sample."

Separate reporting of data by demographic variables, such as age and sex, facilitate pooling of data for subgroups across studies and should be routine, unless there are compelling reasons not to stratify reporting, which should be explained.

\section{$f$. Discussion}

It is useful to begin the discussion by briefly summarizing the main findings, and explore possible mechanisms or explanations for these findings. Emphasize the new and important aspects of your study and put your findings in the context of the totality of the relevant evidence. State the limitations of your study, and explore the implications of your findings for future research and for clinical practice or policy. Discuss the influence or association of variables, such as sex and/or gender, on your findings, where appropriate, and the limitations of the data. Do not repeat in detail data or other information given in other parts of the manuscript, such as in the Introduction or the Results section.

Link the conclusions with the goals of the study but avoid unqualified statements and conclusions not adequately supported by the data. In particular, distinguish between clinical and statistical significance, and avoid making statements on economic benefits and costs unless the manuscript includes the appropriate economic data and analyses. Avoid claiming priority or alluding to work that has not been completed. State new hypotheses when warranted, but label them clearly.

\section{g. References}

\section{i. General Considerations}

Authors should provide direct references to original research sources whenever possible. References should not be used by authors, editors, or peer reviewers to promote self-interests. Authors should avoid citing articles from predatory or pseudo-journals. When preprints are cited, the citation should clearly indicate that the reference is a preprint (also see Section III.D.3). Although references to review articles can be an efficient way to guide readers to a body of literature, review articles do not always reflect original work accurately. On the other hand, extensive lists of references to original work on a topic can use excessive space. Fewer references to key original papers often serve as well as more exhaustive lists, particularly since references can now be added to the electronic version of published papers, and since electronic literature searching allows readers to retrieve published literature efficiently.

References to papers accepted but not yet published should be designated as "in press" or "forthcoming." Information from manuscripts submitted but not accepted should be cited in the text as "unpublished observations" with written permission from the source.

Published articles should reference the unique, persistent identifiers of the data sets employed.

Avoid citing a "personal communication" unless it provides essential information not available from a public source, in which case the name of the person and date of communication should be cited in parentheses in the text. For scientific articles, obtain written permission and confirmation of accuracy from the source of a personal communication.

Some but not all journals check the accuracy of all reference citations; thus, citation errors sometimes appear in the published version of articles. To minimize such errors, references should be verified using either an electronic bibliographic source, such as PubMed, or print copies from original sources. Authors are responsible for checking that none of the references cite retracted articles except in the context of referring to the retraction. For articles published in journals indexed in MEDLINE, the ICMJE considers PubMed the authoritative source for information about retractions. Authors can identify retracted articles in MEDLINE by searching 
Recommendations for the Conduct, Reporting, Editing, and Publication of Scholarly Work in Medical Journals

PubMed for "Retracted publication [pt]", where the term "pt" in square brackets stands for publication type, or by going directly to the PubMed's list of retracted publications (https://www.ncbi.nlm.nih.gov/pubmed/?term= retracted+publication+[pt]).

References should be numbered consecutively in the order in which they are first mentioned in the text. Identify references in text, tables, and legends by Arabic numerals in parentheses.

References cited only in tables or figure legends should be numbered in accordance with the sequence established by the first identification in the text of the particular table or figure. The titles of journals should be abbreviated according to the style used for MEDLINE (www.ncbi.nlm.nih.gov/nlmcatalog/journals). Journals vary on whether they ask authors to cite electronic references within parentheses in the text or in numbered references following the text. Authors should consult with the journal to which they plan to submit their work.

\section{ii. Style and Format}

References should follow the standards summarized in the NLM's Sample References (www.nlm.nih.gov/bsd/ uniform_requirements.html) webpage and detailed in the NLM's Citing Medicine, 2nd edition (www.ncbi.nlm. nih.gov/books/NBK7256/). These resources are regularly updated as new media develop, and currently include guidance for print documents; unpublished material; audio and visual media; material on CD-ROM, DVD, or disk; and material on the Internet.

\section{h. Tables}

Tables capture information concisely and display it efficiently; they also provide information at any desired level of detail and precision. Including data in tables rather than text frequently makes it possible to reduce the length of the text.

Prepare tables according to the specific journal's requirements; to avoid errors it is best if tables can be directly imported into the journal's publication software. Number tables consecutively in the order of their first citation in the text and supply a title for each. Titles in tables should be short but self-explanatory, containing information that allows readers to understand the table's content without having to go back to the text. Be sure that each table is cited in the text.

Give each column a short or an abbreviated heading. Authors should place explanatory matter in footnotes, not in the heading. Explain all nonstandard abbreviations in footnotes, and use symbols to explain information if needed. Symbols may vary from journal to journal (alphabet letter or such symbols as *, $\uparrow, \ddagger, \S)$, so check each journal's instructions for authors for required practice. Identify statistical measures of variations, such as standard deviation and standard error of the mean.

If you use data from another published or unpublished source, obtain permission and acknowledge that source fully.
Additional tables containing backup data too extensive to publish in print may be appropriate for publication in the electronic version of the journal, deposited with an archival service, or made available to readers directly by the authors. An appropriate statement should be added to the text to inform readers that this additional information is available and where it is located. Submit such tables for consideration with the paper so that they will be available to the peer reviewers.

\section{i. Illustrations (Figures)}

Digital images of manuscript illustrations should be submitted in a suitable format for print publication. Most submission systems have detailed instructions on the quality of images and check them after manuscript upload. For print submissions, figures should be either professionally drawn and photographed, or submitted as photographic-quality digital prints.

For radiological and other clinical and diagnostic images, as well as pictures of pathology specimens or photomicrographs, send high-resolution photographic image files. Before-and-after images should be taken with the same intensity, direction, and color of light. Since blots are used as primary evidence in many scientific articles, editors may require deposition of the original photographs of blots on the journal's website.

Although some journals redraw figures, many do not. Letters, numbers, and symbols on figures should therefore be clear and consistent throughout, and large enough to remain legible when the figure is reduced for publication. Figures should be made as self-explanatory as possible, since many will be used directly in slide presentations. Titles and detailed explanations belong in the legends-not on the illustrations themselves.

Photomicrographs should have internal scale markers. Symbols, arrows, or letters used in photomicrographs should contrast with the background. Explain the internal scale and identify the method of staining in photomicrographs.

Figures should be numbered consecutively according to the order in which they have been cited in the text. If a figure has been published previously, acknowledge the original source and submit written permission from the copyright holder to reproduce it. Permission is required irrespective of authorship or publisher except for documents in the public domain.

In the manuscript, legends for illustrations should be on a separate page, with Arabic numerals corresponding to the illustrations. When symbols, arrows, numbers, or letters are used to identify parts of the illustrations, identify and explain each one clearly in the legend.

\section{j. Units of Measurement}

Measurements of length, height, weight, and volume should be reported in metric units (meter, kilogram, or liter) or their decimal multiples.

Temperatures should be in degrees Celsius. Blood pressures should be in millimeters of mercury, unless other units are specifically required by the journal.

Journals vary in the units they use for reporting hematologic, clinical chemistry, and other measurements. Authors must consult the Information for Authors of the 


\section{Unauthorized reproduction of this article is prohibited}

Recommendations for the Conduct, Reporting, Editing, and Publication of Scholarly Work in Medical Journals

particular journal and should report laboratory information in both local and International System of Units (SI).

Editors may request that authors add alternative or non-SI units, since SI units are not universally used. Drug concentrations may be reported in either SI or mass units, but the alternative should be provided in parentheses where appropriate.

\section{k. Abbreviations and Symbols}

Use only standard abbreviations; use of nonstandard abbreviations can be confusing to readers. Avoid abbreviations in the title of the manuscript. The spelled-out abbreviation followed by the abbreviation in parentheses should be used on first mention unless the abbreviation is a standard unit of measurement.

\section{B. Sending the Manuscript to the Journal}

Manuscripts should be accompanied by a cover letter or a completed journal submission form, which should include the following information:

A full statement to the editor about all submissions and previous reports that might be regarded as redundant publication of the same or very similar work. Any such work should be referred to specifically and referenced in the new paper. Copies of such material should be included with the submitted paper to help the editor address the situation. See also Section III.D.2.

A statement of financial or other relationships and activities that might lead to a conflict of interest, if that information is not included in the manuscript itself or in an authors' form. See also Section II.B.

A statement on authorship. Journals that do not use contribution declarations for all authors may require that the submission letter includes a statement that the manuscript has been read and approved by all the authors, that the requirements for authorship as stated earlier in this document have been met, and that each author believes that the manuscript represents honest work if that information is not provided in another form. See also Section II.A.

Contact information for the author responsible for communicating with other authors about revisions and final approval of the proofs, if that information is not included in the manuscript itself.

The letter or form should inform editors if concerns have been raised (e.g., via institutional and/or regulatory bodies) regarding the conduct of the research or if corrective action has been recommended. The letter or form should give any additional information that may be helpful to the editor, such as the type or format of article in the particular journal that the manuscript represents. If the manuscript has been submitted previously to another journal, it is helpful to include the previous editor's and reviewers' comments with the submitted manuscript, along with the authors' responses to those comments. Editors encourage authors to submit these previous communications. Doing so may expedite the review process and encourages transparency and sharing of expertise.

Many journals provide a presubmission checklist to help the author ensure that all the components of the submission have been included. Some journals also require that authors complete checklists for reports of certain study types (e.g., the CONSORT checklist for reports of randomized controlled trials). Authors should look to see if the journal uses such checklists, and send them with the manuscript if they are requested.

The manuscript must be accompanied by permission to reproduce previously published material, use previously published illustrations, report information about identifiable persons, or to acknowledge people for their contributions. 